C i e n 



\title{
El imaginario de la guerra a través del Ienguaje de la televisión y las elecciones presidenciales de 2014 en Colombia*
}

\author{
The Imaginary of War through the Language \\ of Television Reflected in the Colombian \\ Presidential Election of 2014
}

\author{
Víctor Guerrero Apráez ** \\ Santiago José Amaya Rueda ${ }^{* * *}$
}

Recibido: 4 de mayo de 2015

Aprobado: 6 de diciembre de 2016

Publicado en línea: 10 de octubre de 2017

\section{Resumen}

El artículo tiene como objetivo el análisis de las variables tipológicas contenidas en la serie televisiva Tres Caínes y examinar su estrategia representacional mediante una hermenéutica histórica y comparativa que permita dar cuenta de los diversos estereotipos icónico-dramáticos empleados y de una cierta visión del conflicto armado interno en Colombia, para correlacionarlo específicamente con la crucial coyuntura electoral del país en 2014, en cuya primera vuelta el presidente candidato fuera derrotado para sorpresa tanto de encuestadoras como de analistas, acotando su función legitimadora de las propuestas sostenidas por el uribismo y de apoyo mediático. Para este

\begin{abstract}
The article identifies the main characteristics of a specific Colombian television series, Tres Caínes, and relates its political intention - defined by stereotypes and a biased perception of the Colombian armed conflict- with the electoral context of 2014 from a methodological framework composed by historical and comparative hermeneutics in order to scrutinize the correlation between the surprising defeat in the ballot for the president candidate. For this purpose, in first place, the article examines the role of art as a political tool in the 19th and 2oth century, using the examples of the nationalist opera in Germany and Italy and the cinema as propaganda during
\end{abstract}

doi:10.11144/Javeriana.papo22-2.iglt

* Artículo de Reflexión

** Abogado por la Pontificia Universidad Javeriana y magíster en Leyes por la Universität Konstanz. Miembro de la delegación de Colombia a la Conferencia de Plenipotenciarios de Roma para el establecimiento de la Corte Penal Internacional y profesor de planta de la Facultad de Ciencias Políticas y Relaciones Internacionales de la Pontificia Universidad Javeriana de Bogotá. Correo electrónico: guerrerov@javeriana.edu.co ORCID: 0000-0001-9706-3021 *** Facilitador de reincorporación en el grupo territorial de Meta y Orinoquía de la Agencia para la Reincorporación y la Normalización. Correo electrónico: santiagoamaya@acr.gov.co ORCID: 0000-0002-4555-7019 
propósito, en primer lugar, se indaga sobre la funcionalidad del arte como herramienta política en los siglos XIX y XX, tomando como ejemplos la ópera nacionalista alemana e italiana y el cine de propaganda como herramienta de afectación colectivo-perceptiva en el contexto de la Segunda Guerra Mundial; en segundo lugar, se lleva a cabo un acercamiento teórico sobre las características de los géneros televisivos y los entrelazamientos entre realidad y ficción que configuran la serie Tres Caínes como un documento ficcional con pretensiones históricas. Finalmente, se encuentra una relación entre el nivel de exposición al serial (rating), mirado desde una perspectiva geográfica, y el mapa electoral de las elecciones presidenciales de 2014 en Colombia entre el candidato de la Unidad Nacional Juan Manuel Santos y el candidato opositor Óscar Iván Zuluaga.

\section{Palabras clave}

elecciones presidenciales 2014; arte político; televisión; conflicto armado interno, Colombia the Second World War. Secondly, the text presents a theoretical approach towards the main characteristics of television genres and the thin line that separates fiction from reality, constantly crossed in Tres Caínes, that makes the series an attempt of a historical document with elements of fiction. Finally, the research identifies a relationship between the level of exposure to the television series (measured through its rating) in a geographical perspective, and the electoral map of presidential elections in Colombia between Juan Manuel Santos and Óscar Iván Zuluaga.

\section{Keywords}

presidential elections 2014; political art; television; armed conflict Colombia

\section{Cómo citar este artículo:}

Guerrero, V. y Amaya, S. (2017). El imaginario de la guerra a través del lenguaje de la televisión y las elecciones presidenciales de 2014 en Colombia. Papel Político, 22(2), 253-278. https:// doi.org/10.11144/Javeriana.papo22-2.iglt 


\section{Introducción}

Los más de cincuenta años de guerra en Colombia han permeado los espacios más profundos de la cultura colombiana y transformado el lenguaje, las relaciones sociales y nuestra visión de la realidad. Azar (1990), citado por Ramsbotham, Miall y Woodhouse (2011, pp. 68-77), habla de los conflictos socialmente prolongados que superan cierto periodo de maduración y que responden a un contexto social de múltiples causas de conflicto y de diversos actores armados en el entramado de la guerra. Desde esta perspectiva, se acentúa la complejidad del conflicto armado colombiano, muchas veces analizado solo desde un enfoque relacionado con las dinámicas violentas. Sin embargo, los estudios sobre la imagen que ha construido la sociedad colombiana en torno a su propio conflicto son escasos. Partiendo de esta afirmación, este trabajo se estructura con un supuesto teórico: el conflicto armado colombiano, además de sus realidades objetivas, también se manifiesta como una construcción mental en la sociedad que como tal irradia influencias en diversos ámbitos de la vida nacional. Esta segunda dimensión del conflicto representa la creación de un imaginario colectivo en torno a la guerra que puede diferir, en muchos casos, sus condiciones reales y moldear la cultura y la relación entre los colombianos. La brecha entre la guerra y nuestra perspectiva de la guerra no solo es una realidad, sino que resulta relevante para hacer un análisis político de la actualidad y de nuestra historia. Tal vez el ejemplo más claro al respecto sea la relación -o falta de relación- entre las realidades urbanas y las rurales. No resulta extraño, de esta forma, que el habitante de las grandes ciudades no conozca las condiciones reales del campo y se limite a construir su visión de la guerra a partir del imaginario colectivo fabricado por los medios de comunicación, las redes sociales, entre otros.

Este artículo se propone explorar de qué manera se manifiesta la brecha que existe entre la realidad del conflicto y el imaginario del conflicto con la televisión y al mismo tiempo cómo este se proyecta en un ámbito como el de la opinión y el comportamiento electoral. Desde la ciencia política, el estudio resulta relevante por dos razones fundamentales: por un lado, constituye la comprensión del conflicto armado interno desde una perspectiva poco investigada: nuestro imaginario de la guerra; por el otro, resulta pertinente porque ayuda a identificar cuáles son los estereotipos relacionados con la guerra a los que necesariamente se enfrenta una política pública de educación y que se deben eliminar a partir de la formación política de los jóvenes.

Así, su propósito no es hacer una contrastación exhaustiva entre la realidad colombiana y la realidad que propone el medio televisivo, sino determinar las condiciones materiales y mentales sobre las que resultó posible la construcción de una correlación, hasta ahora inexplorada por los estudios politológicos, entre los resultados electorales producidos en la primera vuelta de la elección presidencial de 2014, cuando se escenificó la sorpresiva derrota del candidato presidente con su propuesta de paz frente a su opositor 
que encarnaba la continuación de la guerra, por un lado, y por el otro, la recepción masiva de la serie televisiva Tres Caínes, que mostró las convergencias entre el enorme apoyo a la oposición y la alta cuota de audiencia respecto de dicha serie. Se parte de una contextualización del arte como herramienta política en los siglos cercanos, que empieza por el nacionalismo de la ópera como formador del imaginario del Estado nación en Verdi y Wagner. Luego, se estudia el imaginario como escenario de guerra inmaterial a partir del uso del arte - cine en este caso- como arma de propaganda política en el Tercer Reich y en los países aliados. Posteriormente, se estudia el caso concreto de los Tres Caínes.

La elección de esta serie televisiva no resulta arbitraria y responde a tres razones concretas: 1) el contexto nacional en momentos de la producción y programación de la serie, 2) el movimiento de protesta por parte de las víctimas que se generó después de su salida al aire y 3) el hecho de que Tres Caínes es la primera serie televisiva, desde el boom de programas "basados en hechos reales" del conflicto armado colombiano, que se sale del marco del narcotráfico y desarrolla su argumento en torno a la violencia política (la paramilitar en este caso preciso). Finalmente, se identifican los diferentes estereotipos que consolidan el imaginario y su posterior relación con la coyuntura política y electoral del país. El artículo no busca hallar relaciones causales entre los diferentes fenómenos, sino que su intención radica en explorar la posibilidad de encontrar hechos políticos posiblemente relacionados, con el fin de generar nuevas preguntas y nuevas investigaciones. El estudio finaliza con una serie de conclusiones.

\section{El arte subordinado a la construcción de la identidad política}

\section{Antecedentes: la ópera como vehículo estético del imaginario del Estado nación}

El desarrollo del arte ha estado históricamente relacionado con intereses políticos. Las producciones artísticas, como medios de expresión del ser humano, están íntimamente ligadas a la realidad precisa de cada artista y se ven afectadas por su ideología, sus creencias y sus emociones. Esta afirmación no resulta nada novedosa, pero facilita la comprensión de distintas corrientes y obras de arte a partir de un análisis profundo del contexto político y social donde se producen. Así, sin la necesidad de remontarse a la Antigüedad, el caso de la producción de ópera del siglo XIX se presta como un ejemplo bastante ilustrativo.

La ópera del siglo XIX, siguiendo la conceptualización teórica del compositor alemán Richard Wagner, se presenta como el arte total de la época (Gesamtkunstwerk). El concepto que propone Wagner se explica, según la Enciclopedia Meyer (2004), como la "reunión de poesía, música, danza y artes plásticas en una obra de arte unitaria" (citado por Keska, p. 298). La ópera como unificadora de las artes resalta su importancia en la cultura europea del siglo XIX. Sin embargo, el punto interesante para este análisis reside en su utilización como herramienta política. 
Para mediados de siglo, Italia y Alemania eran las únicas dos grandes naciones de Europa Occidental que todavía no habían logrado su unificación. Desde la ópera, Giuseppe Verdi y Richard Wagner aparecen como los portadores de la voz nacionalista de ambos países. El surgimiento de los dos compositores en la escena política es difícilmente una coincidencia. Como lo señala Sanguinetti (2001, p. 15), "[Wagner] quería ver la unidad alemana como Verdi la italiana”. Este último, desde su esquina, promulgaba el nacionalismo italiano guiado por las voces de su Va, pensiero, coro del tercer acto de su ópera Nabucco (1836), que rápidamente se convertiría en un himno: "Oh mia patria sì bella e perduta!” (iOh, mi patria, tan bella y perdida! Wagner, por su parte, hacía alarde de la tradición alemana, componiendo el monumental Anillo del Nibelungo (1876), cuatro óperas que rinden homenaje a la mitología alemana, su heroísmo y su poder. Hitler, décadas después, retomaría la obra de Wagner y la utilizaría para el mismo propósito: exacerbar el sentimiento nacionalista de superioridad alemana. Ambos compositores representan un hito clave para la unificación de sus respectivas naciones en Estados nación. Desde el ámbito de la ópera, las composiciones influyen en la realidad política e impulsan un movimiento unificador. El conjunto del proceso de construcción nacional y la edificación de una identidad nacional compartida o, según Anderson (1991), el papel determinante desempeñado por la ópera para apuntalar los contenidos imaginarios compartidos con un medio y un medium capaz de agenciar todos los registros sensoriales en celebraciones que congregaban periódicamente grupos poblaciones es lo que promueve el imaginario de los Estados nación, donde la ópera se convierte en el vehículo estético de configuración de la identidad nacional. Wagner y Verdi, desde la corriente artística más influyente de la época, elaboran un determinado tipo de arte operístico, cuyas potencialidades estéticas y de difusión resultan esenciales para contribuir a uno de los procesos políticos más significativos del siglo XIX: la unificación de Italia en 1861 y la de Alemania en 1871.

\section{El cine como arma política: Hollywood vs. Babelsberg}

Para mediados del siglo XX, el cine suple las expectativas que Wagner tenía en la ópera. Riciotto Canudo (1995), uno de los primeros grandes teóricos del cine, afirmaba la posibilidad de encontrar en este la oportunidad para crear la obra de arte total. Canudo fue el primero en asignarle al cine el apelativo de séptimo arte, confiando en su capacidad de sumar los otros seis: música, danza, poesía, arquitectura, escultura y pintura. Sin embargo, con la llegada del Tercer Reich, se produce un punto de quiebre entre ópera y cine. El régimen totalitario se apropia de los medios de expresión artística, los usa como mecanismos de propaganda y elimina la autonomía del artista en relación con su producción (cosa que tampoco resulta nueva si miramos el realismo socialista soviético, por ejemplo). El nacionalsocialismo restringe la libertad de 
expresión y así logra unificar la corriente artística bajo los principios de propaganda al régimen y el nacionalismo alemán.

El tantas veces citado - confesa o inconfesadamente- Joseph Goebbels como ministro de propaganda de la Alemania nazi definió cuasicanónicamente los once principios de la propaganda y su traslación puntillosa como decálogo de la crucial producción cinematográfica que como parte de la campaña militar hubo de encomendarse a los Babelsberg Studios ubicados en las cercanías de Berlín (el equivalente al Hollywood estadounidense de la época tanto como a la Cinecittà italiana y al Mosfilm soviético). Estos grandes complejos industriales de la producción icónica en serie y estrictamente reglamentada a la manera del "ala imaginaria o fantasmagórica" como complemento de la industria bélica representaron la utilización de la estética del cine como herramienta de promoción política de los valores del régimen que contribuyó de modo sustancial a lo que Benjamin (2003) denominaría la "estetización de la política”. A continuación, se expondrá de manera breve la aplicación de algunos de los once principios, tomando como base la película Jüd Suss (Harlan, 1940). La película trata el tema de la supuesta amenaza judía en el siglo XVIII en el ducado de Stuttgart. De carácter abiertamente antisemita, el film es una clara demostración de la utilización del arte con fines políticos y adoctrinadores en el contexto del Tercer Reich.

La película presenta la historia del duque Karl Alexander von Württemberg y su relación con el judío Joseph Süss. Después de que Württemberg hace su juramento como duque, el judío Süss Oppenheimer gana la confianza del aristócrata con préstamos monetarios. Por medio de manipulaciones y mentiras, logra entrar en Stuttgart - a pesar de la ley que prohíbe la entrada de judíos-y llega a convertirse en el máximo consejero del duque, por encima del consejo de la ciudad. Süss llega a ser extremadamente poderoso muy rápido y, con políticas que responden al estereotipo del judío avaro y ambicioso, provoca una guerra civil. Los once principios de Goebbels, citado por Fernández (2011), se pueden detectar nítidamente en el trasfondo de la trama. Veamos algunos.

Uno. Principio de simplificación y del enemigo único. Adoptar una idea única, un único símbolo. Individualizar al adversario en un enemigo único.

Dos. Reunir diversos adversarios en una sola categoría o individuo. [...]

Cinco. Principio de la vulgarización. Toda propaganda debe ser popular, adaptando su nivel al menos inteligente de los individuos a los que va dirigida. Cuanto más grande sea la masa a convencer, más pequeño ha de ser el esfuerzo mental a realizar [...]

Seis. Principio de orquestación. La propaganda debe limitarse a un número pequeño de ideas y repetirlas incansablemente. [...] Si una mentira se repite lo suficiente, acaba por convertirse en verdad [...] 
Nueve. Principio de la silenciación. Acallar las cuestiones sobre las que no se tienen argumentos y disimular las noticias que favorecen el adversario [...].

El judío Süss es una representación de todo el pueblo judío y Goebbels lo utiliza como el enemigo único útil al régimen de Hitler. La idea es bastante sencilla, pero resulta fuertemente poderosa. El nacionalismo alemán, ligado a la creencia de la superioridad racial alemana, se consolida como el símbolo y la idea única que propone Goebbels en el principio 1. Posteriormente, según los principios 1 y 2, se reúnen todos los posibles enemigos del régimen en una sola categoría que representa el demonio por exorcizar de la sociedad: la amenaza judía. Además, se elimina todo tipo de posible complejidad al antisemitismo y se utilizan vulgares simplificaciones, basadas en estereotipos de acuerdo con el principio 5. Así, los judíos en la película son todos avaros, ambiciosos y mentirosos. Incluso, el estereotipo se lleva todavía más lejos y caracteriza a los personajes judíos de manera caricaturesca acorde con su apariencia física. De esta forma, todos tienen una apariencia repugnante, están siempre sucios y tienen voces exageradas. El rabino es tal vez el personaje más cercano a una caricatura en toda la película. Sus ropas manchadas, su aspecto sucio y su nariz abultada son seguramente el mejor complemento a su falta de ética y a su disposición a engañar al duque cuando Süss se lo propone. El rabino es más un estereotipo que un personaje, que un individuo. Sus rasgos exagerados son intentos de deshumanización; el rabino no es una persona, no es un ser humano, es solo un judío, es solo una amenaza.

Así, el cine aporta elementos que permiten hacer una lectura de la realidad de acuerdo con los intereses políticos de quienes manejan las productoras. La configuración de una realidad maniquea se facilita por medio de las técnicas cinematográficas que logran polarizar entre bandos blancos y negros - buenos y malos- un contexto sociopolítico complejo y lleno de matices grises. Esto se debe a la capacidad que tienen los realizadores de contar lo que quieren contar y callar lo que quieren callar (véase principio 9 de Goebbels). Los judíos son caricaturizados según un estereotipo que por definición carece de contenido empírico, y aparecen como seres infrahumanos y malvados. Los alemanes, acorde con el discurso de la superioridad aria, no solo son elegantes y educados, sino que también se caracterizan por su honor intachable. "No quiero venganza. Quiero tan solo justicia. [...] Ojo por ojo diente por diente, esa no es nuestra manera de hacer las cosas". Esta frase, pronunciada por el padre de Dorothea (la joven violada por Süss), recalca la superioridad moral del alemán y sirve como demostración de la visión maniquea que propone la película. "Nuestra manera de hacer las cosas" supone la composición de la realidad a partir de un "ellos" y un "nosotros". "Ellos" son los malos y los ruines. "Nosotros", los buenos, no podemos rebajarnos a ser como "ellos" porque somos superiores.

El cine termina por construir una idea homogeneizante que reúne a toda la sociedad bajo el significante vacío de nacionalsocialismo y se fortalece por la supuesta existencia 
de un enemigo común al que se le culpa de todos los males de la sociedad: el pueblo judío (Laclau, 2005). Guerrero (2012, p. 58), al argumentar la estrecha relación que existe entre cine y guerra, explica el carácter “avasallador" - en sus propias palabrasque poseen ambos. La guerra por medios violentos, y el cine por medios audiovisuales, se encargan de imponer visiones del mundo y de crear o eliminar percepciones que tienen los espectadores frente a diferentes fenómenos de la realidad.

Lo interesante de toda la producción del cine alemán subordinado al régimen nazi cobra un sentido extra a partir del análisis de su contraparte: el cine estadounidense. Ambas potencias, cada una desde su lado del espectro ideológico y sus diferencias de régimen político, se suman en una doble carrera tecnológica alimentada por la guerra. Por un lado, ambos países se encuentran en medio de una carrera armamentística dentro de la lógica de la Segunda Guerra Mundial. Así, mientras Hitler exhibe con orgullo sus panzers, Roosevelt presenta con vanidad sus M10 Wolverine. Sin embargo, existe una lucha diferente de la realidad física de la guerra, una la lucha por la inmaterialidad y la percepción: la guerra de los imaginarios. Así, no solo importa quién tenga la mejor arma, sino también quién sea capaz de mostrar más poder con los medios audiovisuales y quién tenga la mayor incidencia sobre la mentalidad de un público a la vez espectador de la guerra y del cine.

El cine se presenta como arma esencial de esta disputa. De esta forma, mientras Hollywood se aventuraba con superproducciones como Lo que el viento se llevó (1939), Babelsberg respondía, unos años después, con enormes inversiones como Las aventuras del barón Münchhausen (1943). Se trata de una carrera cinematográfica por apropiarse de los imaginarios. Todo se explica con una ecuación bastante simple: cuanta mejor calidad tenga mi cine en comparación con el de mi enemigo, más posibilidades tengo de apoderarme del imaginario del espectador y más posibilidades de ganar la guerra. En conclusión: a mejor cine mayor demostración de poder.

Así, el uso del cine como medio de propaganda y como mecanismo de guerra no se reduce al caso aislado del Tercer Reich. Los Estados Unidos desempeñaron, a lo largo de todas sus guerras, el mismo juego y el cine de Frank Capra, con el monumental Why we fight (1942), es una demostración contundente de este principio. Capra no utiliza la ficción para apoderarse del imaginario del espectador, sino que su técnica es más directa, más cruda. Con una serie de documentales, busca mostrar los horrores de la guerra nacionalsocialista. La técnica visual parece hacer una oda a la destrucción. Bombas explotan, armas se disparan, gente muere. Capra no es sutil en el uso de la imagen. Una voz en off lee el listado de países caídos en la desgracia de la guerra mientras la cámara muestra cadáveres superpuestos unos sobre otros, ruinas de lo que antes eran ciudades, aviones que caen y estallan. El mensaje es directo y está explícito al comienzo del documental. 
El propósito de estos films es dar información sobre los hechos, las causas y los eventos que llevaron a nuestra entrada a la guerra, al igual que los principios por los cuales estamos combatiendo. Estamos determinados a que antes de que se ponga el sol sobre esta terrible lucha nuestra bandera sea reconocida a lo largo del mundo como símbolo de libertad por un lado... y de poder abrumador por el otro.

Las palabras destacadas por el mismo director se refieren a la libertad y el poder. El apoyo al film fue tan grande que recibió un premio de la Academia a mejor documental. Capra no usa rodeos en su utilización del cine como herramienta al servicio de la guerra. No importa entender a qué métodos recurre cada bando. Interesa sí comprender de qué manera, sin importar si régimen democrático o totalitario, si economía capitalista o planificada (como el caso de la antigua URSS), si nazi o aliado, etc., todos los gobiernos han utilizado los medios audiovisuales como arma para manipular la mente del espectador y apoderarse de sus campos de percepción.

\section{Entre la realidad y la ficción}

\section{La televisión: su alcance y su incidencia en la audiencia}

Hasta ahora se ha abordado el tema del arte como herramienta política en diferentes contextos. Llegado este punto, resulta relevante plantearse un interrogante: ¿es la televisión un arte? Sin las pretensiones de responder exhaustivamente a esta duda, que merecería un análisis desde la comunicación y las artes, vale la pena recurrir a los planteamientos de Machado (2000, p. 61). En su argumentación, se muestra como un firme defensor de la televisión. La tesis principal del autor afirma la necesidad de reconfigurar nuestra comprensión del fenómeno televisivo, muchas veces incomprendido. Al preguntarse acerca del carácter artístico de la televisión, asegura que "no vemos nada porque nos rehusamos a ver, porque nos quedamos ciegos cuando encaramos la televisión. Las experiencias están allí, muchas de ellas tan grandes y fuertes como el cine de Welles o de Eisenstein” (p. 65). Este autor intenta incluso abordar el debate ya mencionado en páginas anteriores sobre la consecución de un arte total.

En el siglo XIX Wagner decía que la ópera era la síntesis de todas las artes. Más tarde Eisenstein reivindicó para el cine ese poder de condensar todas las otras formas de expresión.

Hoy, el director inglés Peter Greenaway considera que la televisión cumple ese papel. (p. 75)

Con la existencia clara de una falta de consenso en cuanto al carácter artístico de la televisión, este artículo no busca unirse al debate ni adoptar una postura concreta. Para sus objetivos específicos, resulta importante comprender dos puntos. Sin importar 
que sea arte o no, 1) la televisión, entrada la década de 1950, reemplaza al cine como principal medio audiovisual, es aquí donde reside el punto principal que diferencia el cine y de la televisión para los propósitos específicos de este estudio: el alcance poblacional es mucho mayor en el medio televisivo; y 2) la televisión tiene la posibilidad, al igual que el cine, de forjar o representar imaginarios en las diferentes sociedades.

\section{Tres Caínes: la imposición de una lectura de la realidad como verdad histórica}

La estructura de la industria de televisión colombiana está conformada por un oligopolio de los dos canales privados, RCN y Caracol, que alcanzan una audiencia de $60 \%$ del total de los televisores prendidos en horarios prime time en el país. Fuenzalida (1998) le atribuye la crisis de la televisión pública en el país a la falta de competitividad: "El alto costo de la producción y la necesidad de grandes inversiones han producido el efecto de concentrar en pocas programadoras la capacidad real de programar" (p. 3). Esto supone un escenario desigual, donde la programación producida por intereses privados es la que tiene un mayor alcance poblacional (globalizado cuando las producciones son vendidas al exterior). Más adelante se retomará el tema de las audiencias y el alcance. Por ahora es importante comprender de qué manera los canales privados emiten su programación poniendo sus intereses comerciales y políticos por encima de la responsabilidad social que conlleva la emisión televisiva.

Tres Caínes, dentro este modelo globalizado de televisión privada, pertenece al Canal RCN. Narra la historia de los hermanos Castaño Gil, uno de los casos más paradigmáticos y violentos del involucramiento de una dinastía familiar como actor contrainsurgente y paraestatal dentro del complejo conflicto armado colombiano. Fidel, Vicente y Carlos son los protagonistas de la narración. Después del secuestro -y posterior asesinatode su padre por parte de la guerrilla en el departamento de Antioquia, los tres hermanos emprenden una venganza personal que llevaría años después a la conformación de las Autodefensas Unidas de Colombia (AUC), el principal grupo contrainsurgente del país y al que se ha considerado como el mayor responsable de las cotas de violencia de finales de la década de 1990 y comienzo de la primera década del siglo XXI, ${ }^{1}$ caracterizados por niveles de crueldad insospechados que han sido calificados, judicialmente, por las propios tribunales del país como crímenes de lesa humanidad.

El surgimiento de la serie responde a la evolución histórica de la televisión colombiana. Williams (1989, p. 69) asegura que la violencia ha sido un medio de entretenimiento mucho más viejo que el desarrollo mismo de los medios audiovisuales. Esta afirmación

\footnotetext{
${ }^{1}$ Se estima que entre 1980 y 2012 alrededor de 11751 civiles murieron en masacres. De estos, 7160 (61.8 \%) fueron asesinados por grupos paramilitares, encabezados por las AUC (Centro Nacional de Memoria Histórica [CNMH], 2013, p. 48).
} 
exime de toda responsabilidad a la televisión en cuanto a los contenidos violentos que reproduce. Sin embargo, en su texto, Williams se refiere a la televisión de ficción. ¿Qué sucede cuando la ficción se confunde con la realidad?

Los últimos diez años representan un cambio en la televisión de entretenimiento nocturno en Colombia. Las popularmente llamadas telenovelas -más adelante retomaremos el debate conceptual- cambian en 2004 sus temáticas habituales. La aparición de La viuda de la mafia representa un punto de quiebre y significa el surgimiento y posterior boom de las muchas veces llamadas narconovelas. En pocos años, el tema del narcotráfico invade los horarios prime time de las casas colombianas. El Capo (2009), Las muñecas de la mafia (2009) y Sin tetas no hay paraíso (2006) son algunos de los más exitosos títulos sobre este nuevo subgénero de la televisión en Colombia.

Sin embargo, en un principio, las historias violentas que se apoderan de los televisores colombianos se enmarcan de manera sencilla en el género de ficción. La llegada de El cartel de los sapos (2008), basada en la autobiografía del exnarcotraficante Andrés López, cambia el panorama y vuelve difusa la línea que separa la realidad de la ficción, el relato histórico de una narración producto de la imaginación. Esto representa otro punto de quiebre que problematiza aún más la polémica de la violencia como principal protagonista de la pequeña pantalla. Posterior a esta, producto de la nueva moda impuesta por el relato de López, comienzan las producciones de Escobar, el patrón del mal (2012) y Alias el Mexicano (2013), entre otras biografías televisadas - con tintes de ficción- de los capos del cartel de Medellín, Pablo Escobar y Gonzalo Rodríguez Gacha, respectivamente. Tres Caínes complementa la lista de híbridos entre relatos históricos e imaginativos, entre narraciones de memoria y documentos históricos, entre realidad y productos de ficción. ¿Qué sucede cuando la verdad histórica queda al servicio de los intereses comerciales de una cadena televisiva? ¿No resulta peligroso que el relato histórico lo maneje la televisión privada? ¿No parece esto más absurdo aún en contextos de conflicto armado?

Dentro de un régimen comunicativo monológico en su temática y altamente monopólico en las estructuras mediales de producción, de acuerdo con López de la Roche (2013, 2014), como el colombiano, cristalizado con sus rasgos dominantes desde 1998 con la privatización absoluta de los canales televisivos por parte de empresas multinacionales y emporios nacionales, la producción de series televisivas hizo suya la creatividad introducida por las nuevas telenovelas de mediados de la década de 1990 (la telenovela de ruptura, como la denominara Martín-Barbero [2003], que renovó estilísticamente el género), pero en esta ocasión puesta al servicio de la demonización de las guerrillas y la exaltación apologética, no exenta de espurios tintes bíblicos, de los grupos paramilitares. Bajo tales condiciones, bien poco podían influir en la opinión del electorado los informes del Grupo de Memoria Histórica que documentan académicamente la barbarie paramilitar con la serie televisiva Tres Caínes que los escenifica como defensores del bien. 
Mas Manchón (2011) hace una crítica a la tipología clásica de géneros televisivos que resulta pertinente para ilustrar el problema de hibridación entre realidad y ficción que presenta Tres Caínes. Además, explica que los géneros son producto de la necesidad de agrupación de mensajes artísticos o informativos que presenten características que los hagan comunes (p. 78). A partir de esta definición, explica la tipología que construye Harold Lasswell en 1948 y asegura que viene perdiendo vigencia con el desarrollo del medio. Para Lasswell, la televisión reproduce tres géneros de programas: de información, de ficción y de publicidad. Sin embargo, más de medio siglo después, la clasificación no resulta tan simple. Veamos.

Según la tipología de Lasswell, los programas de información están claramente definidos por parámetros que los hacen identificables. Noticieros, programas de historia y documentales son tal vez los principales exponentes del género. Con la publicidad sucede algo parecido. Cualquier propaganda que busque lograr una venta o promocionar alguna idea que produzca reacción en el público sería publicidad. Según esta afirmación, la publicidad iría, desde un comercial que busca la venta de un producto de aseo, hasta una campaña política, siempre cumpliendo con querer vender un producto o una idea. En cuanto a la ficción, el género recoge todo tipo de programación que reproduzca historias que simulan la realidad a partir de mundos imaginarios (Lasswell, citado por Mas Manchón, 2011, p. 79). Este es el caso de los telemovies, o series, como Tres Caínes. Hasta este punto la división parece bastante clara, siempre y cuando la programación cumpla con los requisitos de la tipología. Sin embargo, ya nos hemos planteado una pregunta: ¿qué sucede cuándo se hace difusa la división entre las características de los diferentes géneros? Antes de responder a esta pregunta, ubiquemos la serie analizada dentro de un género y subgénero específico.

Según sus características, Tres Caínes puede clasificarse como una serie televisiva (soap opera). Sin embargo, el debate en cuanto a la traducción del término no es tan claro, y autores como Tufte (2007, p. 90), por ejemplo, entienden lo mismo por soap opera, serie televisiva y telenovela. Para propósitos de este estudio, no es relevante discutir sobre el debate de conceptos y adoptamos la posición de Medina y Barrón (2010, p. 77), que afirman que las telenovelas son las versiones latinoamericanas de las soap opera, traducidas originalmente como series televisivas. Las características de las soap operas latinoamericanas son variadas, pero deben cumplirse con algunas básicas. Para las autoras, el principal requisito es que sean del género de ficción (p. 79). Además, deben contar con capítulos con historias conectadas por la misma línea argumentativa, emitidos discontinuamente (en general de manera diaria), que presentan personajes simples, con estereotipos apasionados, que actúan guiados por sus sentimientos. Machado (2000) agrega que su formato discontinuo y fragmentado - contrario a la narrativa cinematográfica basada en leyes de continuidad-sirve para 
enganchar al televidente día tras día, y cada capítulo acaba cuando se produce una tensión. Esta discontinuidad, además, está estructurada para que perderse un día de la serie no impida la comprensión de la trama. Machado afirma que los capítulos no están encadenados por nexos absolutos de causalidad (p. 340), y compara a las series con la novela Rayuela, de Julio Cortázar (tan solo en el formato), donde el desorden y saltarse capítulos no altera el resultado de la obra.

Martín-Barbero (2003, p. 131) añade que las soap operas latinoamericanas cumplen el papel de representar los valores culturales locales del país de emisión. En palabras de Tufte (2007), "la telenovela se convierte en una forma importante de ejercitar la ciudadanía cultural [...] transformando el uso de las telenovelas en un proceso que promueve la pertenencia y la ciudadanía” (p. 107). El arraigo cultural de la telenovela, al reproducir estereotipos sociales propios de las sociedades y reproducir su cosmovisión, logra una identificación emocional entre el televidente y los personajes de las soap operas. Esta identificación, este reconocimiento del yo en el personaje de ficción, explica la gran popularidad que presentan las telenovelas en términos de rating y dan luces de la enorme incidencia que tienen los contenidos de las soap operas en la realidad política de los países. Este es el caso de Tres Caínes. Como lo diría Tufte en su argumentación, "las telenovelas, debido a su amplia popularidad en los países latinoamericanos, constituyen un más importante y relevante instrumento de educación que los programas noticiosos o la publicidad social” (p. 104).

Tres Caínes cumple a cabalidad todos los requisitos expuestos arriba, excepto uno: su fidelidad al género de ficción. Esto responde a la crítica que Mas Manchón hace a la tipología clásica de los géneros televisivos que habíamos mencionado en párrafos anteriores. La argumentación es sencilla. La tipología clásica pierde vigencia, porque el desarrollo del medio televisivo vuelve difusas las fronteras entre un género y el otro. Es una cuestión de hibridación entre géneros. La ficción se confunde con la información, la información con la publicidad, y viceversa. Las características ya no están claramente separadas y se comparten entre los géneros clásicos. Así, un programa de ficción como Tres Caínes se puede mover entre la imaginación de los libretistas y la información que pretende transmitirse al asegurar que el relato está construido con testimonios dados por paramilitares dentro del proceso de justicia y paz, reglamentado por la Ley 975/2005, de 25 de julio. Según Mas Manchón (2011, p. 78), Tres Caínes cabría dentro de los programas de frontera que presentan una hibridación entre ficción e información. Esta es definida por el autor como "la creación de mundos posibles del desorden del imaginario, pero anclados en la realidad, con la subsiguiente difuminación de las fronteras entre realidad y ficción".

El párrafo aclaratorio, antes de comenzar cada capítulo de la serie, resulta bastante ilustrativo para comprender el fenómeno de hibridación: 
El siguiente programa contiene escenas de violencia que, examinadas dentro de un contexto histórico y social, dan a conocer y representan sucesos de una época que alteró y afectó gravemente al pueblo colombiano.

La serie Tres Caínes está basada en testimonios rendidos en los diferentes procesos adelantados a partir de la Ley de Justicia y Paz, en las investigaciones y entrevistas realizadas por el autor de la serie, Gustavo Bolívar Moreno y el periodista Alfredo Serrano Zabala, así como en las informaciones de medios de comunicación, artículos de prensa y hechos de público conocimiento. Los hechos que se narran y presentan contienen personajes y situaciones de ficción.

Este es fundamental para entender la naturaleza de la telenovela. Como queda claro, Tres Caínes es una serie basada en hechos reales, pero con pinceladas de ficción. Las graves críticas respecto de su contenido han llevado a los productores de RCN a pasar la aclaración citada más arriba, al comienzo de cada episodio. Es una forma de lavarse las manos. Otras series similares e igual de criticadas, como Escobar, el patrón del mal (2012), han llevado a los realizadores de la producción a justificar sus contenidos de violencia con la frase "el que no conoce su historia está condenado a repetirla", pronunciada en voz grave y seria al comienzo de cada capítulo. Con el argumento de conocer la historia, se justifica la programación de series que imponen una interpretación parcializada de fenómenos históricos como un documento de historia oficial.

Con Tres Caínes sucede lo mismo. El párrafo aclaratorio tiene evidentes propósitos de vender la serie como producto de una investigación seria, como documento con verificación empírica basada en hechos reales. Se habla de "testimonios de Justicia y Paz”, de “investigaciones y entrevistas”. Incluso parece que se hablara de una revisión de prensa exhaustiva. Es evidente que la serie asegura narrar la historia tal y como sucedió. Sin embargo, el párrafo acaba con una pequeña frase que hace las veces de chaleco antibalas, que exime de todo tipo de responsabilidad histórica al canal, teniendo en cuenta la posibilidad de ofender a las víctimas e incluso revictimizarlas negándoles su derecho a la verdad: "Los hechos que se narran y presentan contienen personajes y situaciones de ficción”. Esto tiene serias implicaciones. Por un lado, la producción juega a contar hechos reales, a producir un documento cuasiacadémico que "cuente nuestra historia para no repetirla”. Por el otro, de manera sagaz, se lavan las manos diciendo que la historia tiene sus matices de ficción. ¿Dónde separamos la ficción de la realidad? ¿Qué hacer ante los reclamos de los hijos de Bernardo Jaramillo Ossa -Fernando Jaramillo en la serie- cuando afirman que su padre no era el cobarde agachado ante Pablo Escobar que retrata la telenovela? Todos sabemos que no lo era. ¿Dónde quedó el dirigente de la Unión Patriótica que una vez, valiente, aseguró saber que su muerte era cuestión de meses y aun así se negó a detener su lucha política? En los Tres Caínes, no existe. La 
serie, arbitraria, se permite ese tipo de lujos narrativos cobijado bajo la protección de representar "personajes y situaciones de ficción".

El conflicto se hace evidente en forma de pregunta: ¿cómo hace el televidente para separar la verdad de la mentira, la realidad de la ficción, la historia de la interpretación de la historia? Este es un interrogante tal vez sin respuesta. Las cadenas televisivas ganan millones a costa de vender información que distorsiona la realidad en la mente del espectador, que le impone una sola versión de la historia como la verdadera y que ayuda a institucionalizar los estereotipos de la guerra en la mente del televidente.

\section{La oposición de dos perspectivas en disputa: una batalla desde el alcance de la pequeña pantalla al mapa electoral}

Es evidente que la creación y consolidación de imaginarios paralelos en la mentalidad colombiana, construidos sobre estereotipos y generalizaciones, representan un problema en la manera como se configura y se entiende la realidad política. Sin embargo, ¿qqué alcance tiene la propagación de dichos imaginarios? ¿Cuál es la incidencia de la televisión como fenómeno de masas en un país como Colombia? Este apartado tiene como objetivo profundizar en este tipo de preguntas. A partir de los datos de rating de Tres Caínes, se pretende mirar cuál es el alcance poblacional de la serie y, de ser posible, dar luces sobre la posible existencia de una serie de correlaciones entre la geografía del rating de la telenovela y los resultados presidenciales de la segunda vuelta electoral de 2014 en Colombia. El propósito es hacer una aproximación del nivel de exposición - rating - del imaginario de la guerra que promueve la serie y compararlo con las votaciones en Colombia.

Cuando hablamos de rating, nos referimos al porcentaje de televisores de un espacio geográfico específico (hogares de Colombia), durante un tiempo preciso (horario de transmisión de los Tres Caínes), que están emitiendo el programa. El share es la misma relación, pero, en vez del total de televisores existentes, se refiere al total de televisores encendidos.

Según los datos de RCN, durante el periodo de emisión de los Tres Caínes (4 de marzo de 2013-18 de junio de 2013), en el horario promedio entre 9:49:53 p. m. y 10:48:50 p. m., alrededor de $44.1 \%$ de los hogares colombianos con televisión se dedicaron a ver Caracol o RCN. La serie los Tres Caínes, emitida por RCN, representa $27.3 \%$ del total de televisores. Esto, si se recurre a las estadísticas del Departamento Administrativo Nacional de Estadística (DANE, 2005) sobre el número de hogares colombianos con televisión, se obtiene una aproximación del nivel poblacional de recepción de la telenovela. Se parte de los siguientes datos: según la información del censo de 2005 ,

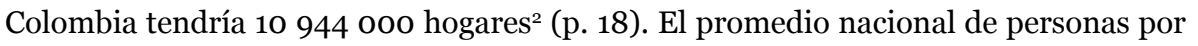

\footnotetext{
${ }^{2}$ Esta cifra hoy se estima más alta. Usar el número de hogares censado en 2005 y contrastarlo con los datos de 2012 nos permitirá hacer una aproximación modesta del alcance de la novela. Esto significa que los números que obtengamos serán menores de los reales, lo cual les da más contundencia a los resultados.
} 
hogar, para 2012, es de 3.5 personas (DANE, 2013, p. 3). Esto implica que alrededor de 38304 ooo colombianos - se sabe que la cifra es menor de la real-componen los hogares colombianos. Del número total de hogares y de colombianos, $91 \%$ tiene acceso a televisión en color (p. 23), lo cual arroja los siguientes resultados. En el país, hay 9959049 hogares y 34856640 colombianos con acceso a televisión. Si esto se contrasta con el rating de 27.3 \%, la aproximación de hogares y colombianos que vieron Tres Caínes sería de 2718820 hogares y 9515862 colombianos. Lo anterior implica que más de uno de cada cinco colombianos estuvo expuesto al programa.

Este nivel de alcance poblacional tiene una serie de implicaciones, porque representa en un número cuál fue la propagación y el nivel de recepción poblacional que tuvo el imaginario de la guerra que promueve la serie. Ya identificamos cuáles son los estereotipos que se desprenden de la telenovela. Sin embargo, falta una pieza fundamental en el rompecabezas: la coyuntura política del país en el momento de producción y programación de Tres Caínes. Para junio de 2011, Juan Manuel Santos apenas comienza su primer gobierno. Es entonces cuando se atreve a cambiar el paradigma de seguridad del gobierno anterior. Santos acepta la existencia de un conflicto armado interno (antes solo visto como narcoterrorismo, es decir, delincuencia común), y su gobierno, por medio de la Ley 1448/2011, de 10 de junio, acepta también la existencia de víctimas y la necesidad de repararlas. Un año largo después, en septiembre de 2012, entabla negociaciones con las Fuerzas Armadas Revolucionarias de Colombia (FARC).

Lo importante de la coyuntura política del país, relacionada con el imaginario que promueve Tres Caínes, es la contraposición de dos perspectivas opuestas en constante disputa: la comprensión de la realidad del Gobierno y la visión que reproduce la serie; por un lado, la posición política de Santos se configura y legitima con el discurso del diálogo y la negociación; por otro, la telenovela parece promover los valores contrarios. Mientras el Gobierno se compromete con un ambicioso plan de reparación y reconocimiento de las víctimas, la serie se propone negar su existencia por medio de la invisibilización. Mientras la víctima pasa a ser el centro de la política pública de la agenda del Gobierno, Tres Caínes parece proponerse glorificar al victimario. Sin embargo, estas relaciones no acaban acá y permiten distinguir una fuerte disputa entre dos posiciones normativas en cuanto al deber ser de la política nacional. Mientras Santos le otorga estatus político y reconoce a las FARC, la serie no se atreve a darles ni nombre y caricaturiza al guerrillero como una máquina pegada a un libreto aprendido de memoria, exento de cualquier ideología. Mientras FARC y Gobierno se proponen dialogar en La Habana, en Tres Caínes, el diálogo solo fracasa y se ridiculiza. La contradicción es evidente y la serie parece ser una respuesta, una reacción a la política de Santos. Tal vez, incluso, Tres Caínes expresa visualmente los intereses de los sectores que se oponen a la negociación. A continuación, se busca comparar la geografía del rating de la serie con 
el mapa electoral colombiano. Más que hallar relaciones causales, se pretende dar luces sobre la posible existencia de correlaciones entre el fenómeno audiovisual y el electoral.

Al revisar las figuras 1, 2 y 3, la relación Tres Caínes-segunda vuelta elecciones presidenciales 2014 cobra algo más de sentido. La figura 1 nos presenta un mapa de Colombia con la geografía del rating de la serie televisiva. Los departamentos con color más oscuro presentan los mayores índices de audiencia; mientras que los más claros, los menores. La figura 2 es el mapa electoral de la segunda vuelta presidencial, donde el color azul representa los votos de la oposición, el Centro Democrático; y el color naranja, la Unidad Nacional en cabeza de Santos. La figura 3 es la unión de los dos mapas, que representa el nivel regionalizado de rating de la serie, con dos opciones, alto o bajo, y tiene los colores de la contienda electoral. A primera vista, encontrar algún tipo de relación de manera visual no resulta sencillo. Incluso, parece que los mapas son prácticamente diferentes. Sin embargo, vale la pena analizarlos.

\section{Figura 1. Porcentaje de rating de Tres Caínes por regiones.}

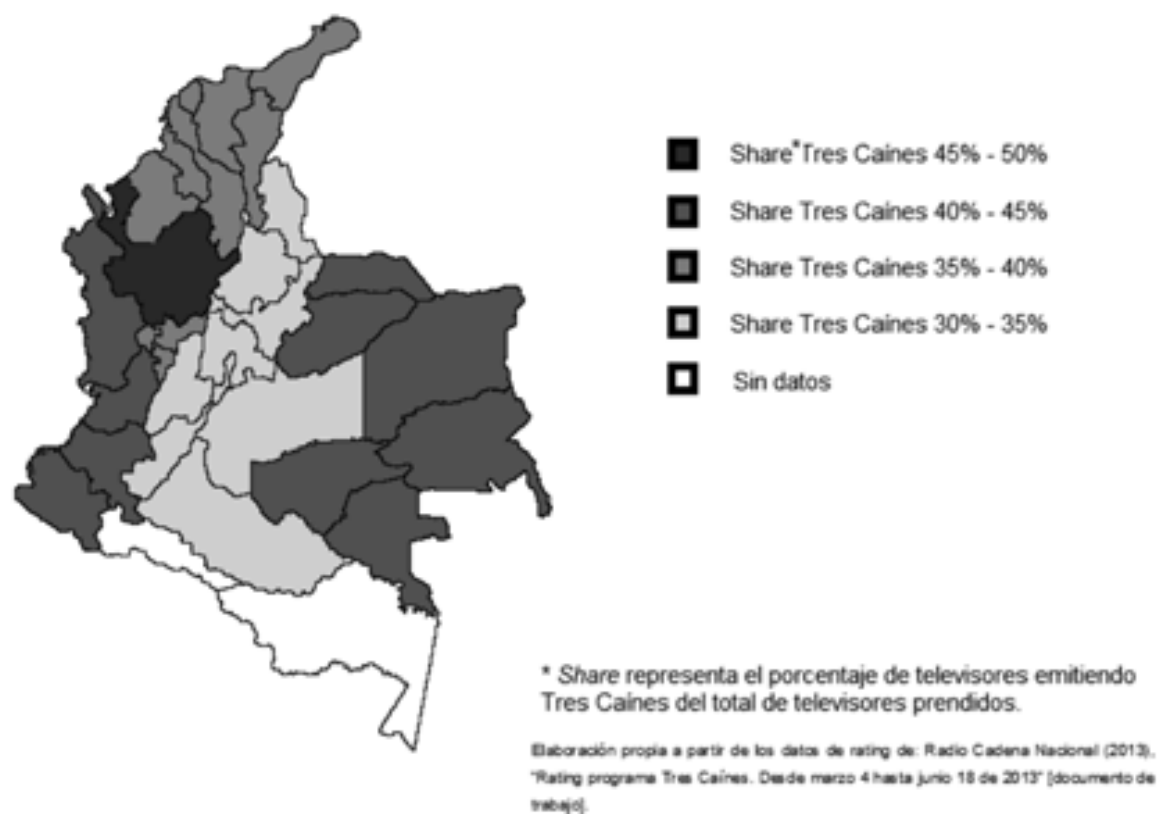

Fuente: Elaboración propia según Rating Colombia (2013). 


\section{Figura 2. Mapa electoral segunda vuelta elecciones presidenciales 2014.}

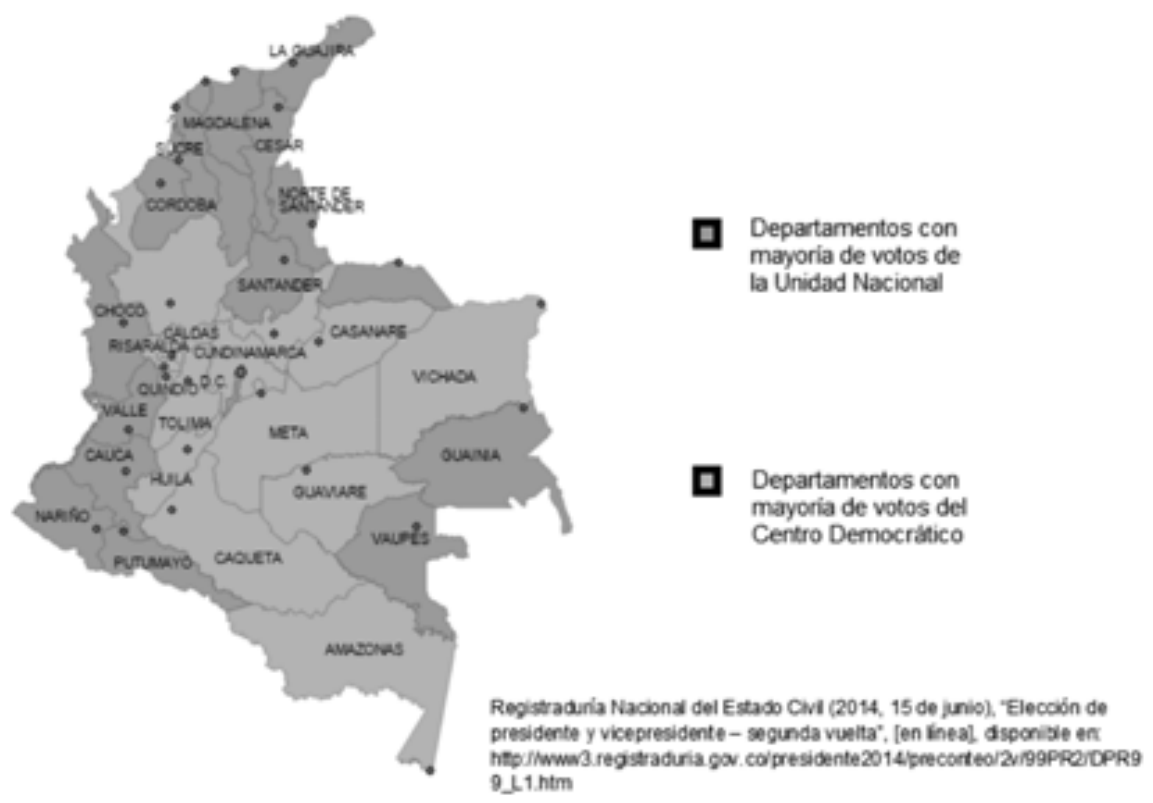

Fuente: Registraduría Nacional del Estado Civil (2014).

\section{Figura 3. Porcentaje de rating de Tres Caínes por regiones.}

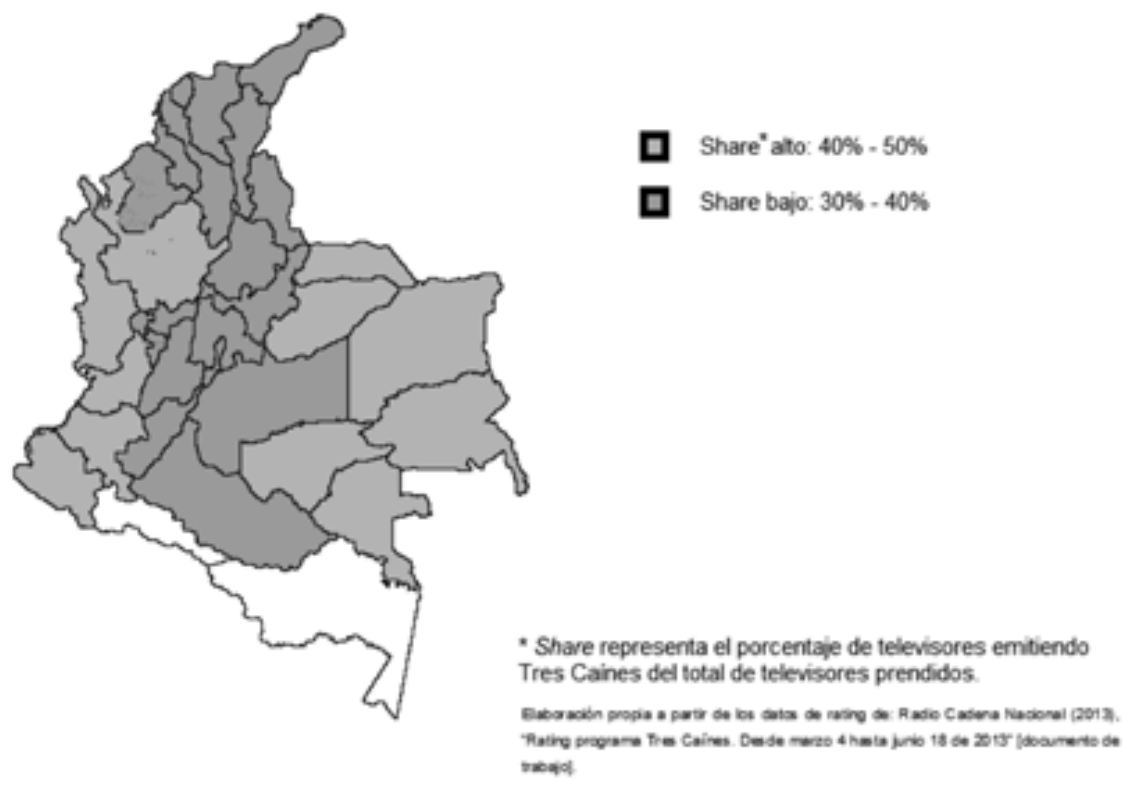

Fuente: Rating Colombia (2013). 
Lo que resulta pertinente desde el análisis es la veracidad de una cartografía de votos. Los colores invaden el mapa y dan una falsa ilusión. Las grandes extensiones, por grandes que sean, no necesariamente cuentan con una alta densidad poblacional. Así, mientras los departamentos del oriente del país tienen extensiones de tierra gigantescas, son los que menos votos le aportan a una campaña. Vichada, por ejemplo, solo le suma 7801 votos al candidato de la oposición. Por el contrario, en pequeños territorios, suelen concentrarse enormes cantidades de población (votos y espectadores). Esto es precisamente lo que explica la primera relación entre la audiencia de Tres Caínes y los resultados electorales. Los mapas no coinciden visualmente, porque la relación entre extensión de tierra y número de votos (televidentes) no está explícita. Analicemos los casos de Bogotá y Antioquia.

El mapa electoral es bastante homogéneo en el centro del país. Todo el centro, salvo Bogotá y los Santanderes, prefirió a Óscar Iván Zuluaga. Sin embargo, es Bogotá donde están los votos. Santos recibe 1337349 votos en la capital. Sin embargo, en el mapa electoral, la región central del país parece ser toda azul. Si sumamos los votos por el Centro Democrático, donde venció Zuluaga, entre Tolima, Huila, Cundinamarca y Boyacá, el este alcanza 1304258 votos. La Unidad Nacional, en cambio, suma 2005516 en la zona. Al parecer, los colores engañan. La región central parece ser naranja, a pesar de lo que dice el mapa. Si se comparan estos resultados con el rating de Tres Caínes, se ve una primera relación. La región central es, según los datos, la que menos estuvo expuesta a la telenovela. Miremos otro ejemplo.

Los analistas de RCN toman como una región al departamento de Antioquia, lo cual seguramente responde a sus altos niveles de audiencia. En este caso, el mapa electoral es más que claro. Antioquia, sin duda alguna, es zuluaguista (uribista, en todo caso). Curiosamente, Antioquia, después de Bogotá, es el segundo banco de votos más grande del país. Tenemos una interesante oposición; por un lado, Bogotá (primer lugar en número de votos) es santista - en esas elecciones- y tiene los índices más bajos de audiencia para Tres Caínes (30.1\%); por otro, Antioquia (el segundo lugar con más número de votos) vota por el Centro Democrático - 1137735 contra 704164 de la Unidad Nacional-y tiene el índice más alto de audiencia de la serie (49.4 \%). Las relaciones siguen haciéndose evidentes. Todo indica que este país está polarizado entre derecha y más derecha.

El análisis se puede, incluso, llevar algo más lejos. Si miramos de nuevo la figura 3, la única zona del país que parece responder con colores a la relación con la figura 2 es la Costa Caribe. A primera vista, esta es santista y no hay ningún departamento ni gran banco de votos, por pequeño que sea en extensión de tierras, que pueda equilibrar la balanza a favor de Zuluaga. La Costa Atlántica votó por Santos, es indiscutible. En total, en la región, Santos alcanza 2005626 votos. Estos, sumados 
a los 2005516 que obtiene la Unidad Nacional en el centro del país, dan 4011144 votos entre ambas regiones. Estas dos regiones, si miramos nuevamente la figura 3, son las que tienen color naranja, es decir, los índices más bajos de rating. Los votos de ambas regiones representan 51.3 \% del total de votos por Santos (7 816 986) en la nación, por lo cual la relación parece consolidarse. La zona que vota por Santos no vio Tres Caínes, mientras que la región que más lo hizo Tres Caínes (Antioquia) vota indiscutiblemente por Zuluaga.

Por último, vale la pena salirse de la cartografía para llamar la atención sobre un punto adicional. La figura 4 nos presenta un fragmento de una encuesta electoral realizada por Cifras \& Conceptos (2014). Ante la pregunta de por quién votaría al encuestado en mayo de 2014 (entre primera y segunda vuelta), estando dividida la respuesta por estrato socioeconómico alto, medio y bajo, los resultados indican que los estratos altos están con Santos (44 vs. 35 \%), mientras que los bajos con Zuluaga (39 vs. $37 \%$ ). Curiosamente, la relación con el rating de Tres Caínes vuelve a ser la misma. Los estratos altos no tienden a ver la serie ( $28 \%$ ), mientras que los bajos son el público con mayor audiencia de la telenovela (41.8 \%). Como se ha repetido varias veces, aunque la idea no es establecer relaciones causales entre fenómenos, sí se repite de nuevo la tendencia. Resulta innegable, eso sí, que, desde las cifras del DANE, la Registraduría, el Canal RCN y Cifras \& Conceptos, se puede visualizar una conclusión: los estratos bajos y la región de Antioquia, que representan los núcleos de mayor audiencia de Tres Caínes, votaron por Zuluaga. Los estratos altos y las regiones caribe y central, que representan los núcleos de menor audiencia de Tres Caínes, votaron por Santos.

\section{Figura 4. Encuesta electoral 2014}

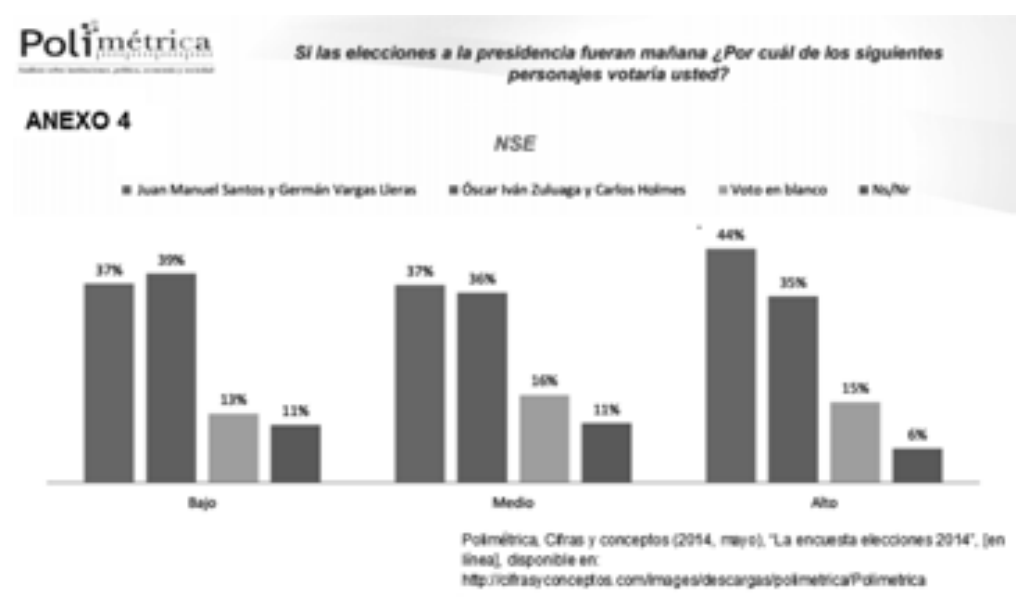

Fuente: Cifras \& Conceptos. 
Resulta evidente que el comportamiento electoral en la región no se puede explicar de manera directa por el nivel de audiencia de la serie Tres Caínes. Sin embargo, la relación sí resulta contrastable entre los dos fenómenos. De esta forma, es posible determinar una correlación: a mayor exposición a Tres Caínes, más probabilidad de votaciones por el Centro Democrático; por el contrario, a menor exposición, menor probabilidad. Es pertinente preguntarse el porqué de la relación, pero la respuesta a ese interrogante requiere otras investigaciones. Es posible dar algunas claridades al respecto. La serie televisa comienza su emisión cinco meses luego del final de Escobar, el patrón del mal y finaliza el 18 de junio de 2013, casi un año exacto antes de la segunda vuelta de las elecciones presidenciales, al comienzo de la campaña electoral. Esto implica que entre mayo de 2012 (primera emisión de la serie biográfica de Escobar) y junio de 2014 (final de Tres Caínes), los televidentes del área de mayor recepción de las narconovelas (que comparten los mismos nichos de audiencia) estuvieron expuestos a 183 horas de creación y consolidación de imaginario (113 de Escobar, el patrón del mal y 70 de Tres Caínes). Este nivel de exposición alimenta la construcción de una identidad propia, con un imaginario paralelo a la realidad estereotipada de las emisiones televisivas. Tal vez, sin saberlo, o sabiéndolo en todo caso mejor que el propio Gobierno en trance de reelegirse, la campaña de Zuluaga había comenzado años atrás con estas series televisivas.

\section{Conclusión}

Los imaginarios culturales y simbólicos que predominan en los públicos colombianos acerca de la representación de nuestro conflicto armado no solo están producidos por un complejo entramado de agenciamientos mediales forjados en la hibridación de múltiples procedencias o linajes iconográficos y visuales (románticos, posmodernos, tradicionalistas, populares), sino que apuntan con diversas intensidades a una estructura segmentada y altamente diferenciada de audiencias, cuya atención y habitual recepción se trabajan con minuciosidad estratégica de marketing en la maximización de su eficacia. En el medio específico de la TV, el imaginario sobre el conflicto armado interno que se proyecta sobre estas audiencias se compone de manera predominante por binariedades elementales de buenos y malos, por cadenas causales simplificadoras de agravio y venganza, por la acuñación de estereotipos comportamentales entre antagonistas esquematizados en sus respectivas relaciones de enfrentamiento, cercanía y adhesión, cuya recepción, tal como se ha podido mostrar en el análisis propuesto de la serie televisiva Tres Caínes, en la cual la composición de estos rasgos alcanza una suerte de paroxismo simplificador y maniqueo, tuvo elevados índices de impacto en las regiones analizadas. El altísimo nivel de recepción experimentado por la serie en el departamento de Antioquia respecto de las demás regiones del país se pudo correlacionar con la decisiva mayoría de la votación electoral depositada durante la 
primera vuelta de las elecciones presidenciales a favor del candidato caracterizado como el acérrimo antagonista al proceso de paz impulsado por el presidente candidato. Por primera vez en la historia electoral bajo el sistema de doble vuelta, el resultado debió definirse en el repechaje, pese al dilatado esfuerzo gubernamental por asegurar un triunfo en la primera; y con mayor énfasis desde el empleo de la reelección en las justas electorales de 2006. Por las especiales circunstancias de la contienda electoral, y pese a que algunas agencias encuestadoras lograron prever la creciente debilidad en la intención de voto por el presidente candidato, el resultado adverso a este en cerca de un millón de sufragios constituyó una mayúscula sorpresa para los analistas políticos y electorales, que influidos por el patrón de comportamiento del electorado presentado en 2006, cuando el entonces candidato presidente arrasó a sus contendores sin tener que llegar a la segunda vuelta, esperaban un desenlace no demasiado distinto de aquel. Respecto del marketing electoral y de las previsiones de comportamiento del elector, el acontecimiento propiamente dicho no consistió en la reelección de Juan Manuel Santos en la segunda vuelta, sino en su derrota en la primera, que como tal no conocía precedente en las seis oportunidades anteriores desarrolladas bajo este sistema. La tesis de fondo de este artículo radica en sostener que la real y efectiva campaña del candidato antigobiernista sobre el electorado colombiano estuvo constituida por los dos años de emisión del par de series televisivas (Escobar, el patrón del mal y Tres Caínes), cuya efectividad en la consolidación y reafirmación de los estereotipos del paramilitar justiciero y el político corrupto terminarían por reportarle las mayorías electorales de votantes requeridas para vencer en las urnas al candidato favorito de los medios escritos que dispuso de la institucionalidad presidencial a su antojo para fraguar su campaña reeleccionista. En otras palabras, el imaginario colectivo sobre una guerra interminable de ajusticiamiento completamente estereotipada contra un enemigo desalmado hasta su caricaturización demoniaca que las audiencias experimentaron les proporcionó la justificación emocional y valorativa para encontrar en el ícono del Zorro - adoptada por la campaña del contendor Óscar Iván Zuluaga y su mentor Álvaro Uribe Vélezla encarnación de sus más hondas adhesiones personales y colectivas en consonancia con aquellas. Quizá como en ninguna otra ocasión en la historia de la política electoral colombiana el voto fue la continuación del encendido del televisor para contemplar la saga belicista de salvación propugnada por la figura de los tres hermanos en abierta y decidida contraposición al discurso de la paz. Como en pocas ocasiones, también pudo evidenciarse que la televisión es en el contexto colombiano una herramienta extremadamente eficaz para la creación y la propagación de una realidad paralela, la realidad de un conflicto que se construye en la mentalidad del espectador a través de los estereotipos analizados que conforman ese particular imaginario que fue el sustrato para el triunfo inicial de la opción a favor de la guerra. 
El objetivo de este artículo fue justamente la identificación de esa realidad paralela producida y reproducida por una soap show muy particular transmitido por un canal privado de televisión con alcance nacional y altísima recepción en las audiencias de la totalidad de la geografía nacional. Pero, especialmente, su verdadera novedad consiste en haber podido documentar académicamente una intensa correlación existente y actuante entre fenómenos de comportamientos de masas -electoral y recepción televisiva - carentes hasta ahora de cualquier tipo de vinculación explicativa. El imaginario se consolida y lleva implícitos una serie de valores y una cosmovisión de la guerra en Colombia que tiene un fuerte carácter normativo - un deber ser- de cómo entender y lidiar con el conflicto dado por su constancia, maniqueísmo y simplificación. Esta realidad paralela niega a las víctimas, caricaturiza a los adversarios, glorifica un proyecto determinado y descarta como impensable una eventual solución negociada del conflicto bélico. Lo interesante en este punto es entender la relación que se produce entre la exposición al imaginario de la serie (porcentajes de rating) y la votación por un proyecto político determinado. Los valores que comparten ambos, desde una mirada superficial a los estereotipos analizados, son fuertemente contrastables. Es evidente, como ya se mencionó, que la relación no es causal, es decir, no puede ubicarse en el ámbito de una linealidad de términos vinculables en forma de causa y efecto, pero que no hay nada en absoluto semejante a una casualidad en la convergencia de la audiencia y su manifestación como electorado. Sin embargo, puede sostenerse que Tres Caínes -en asocio con la serie cronológicamente anterior Escobar, el patrón del mal- promovió, exaltó y actualizó un imaginario particular de amplio arraigo en perfecta consonancia con los rasgos identitarios y los intereses de específicos sectores políticos que fueron decisivos en la creación e imposición de dicho imaginario compartido, incluso de una cosmovisión común. Suficiente para haber producido el hasta hoy mayor sobresalto en el desarrollo de unas negociaciones políticas de la paz en un país que las ha buscado infructuosamente durante más de medio siglo y en el tránsito del siglo anterior al actual. Este resultado electoral inesperado e imposible de prever por los encuestadores de opinión se constituye en el antecedente inmediato del no menos perplejizante desenlace del plebiscito convocado el 3 de octubre de 2016, con el que el mismo Gobierno Santos, en una maniobra claramente instrumentalizadora del proceso de paz, terminaría favoreciendo a los mismos sectores políticos beneficiarios del imaginario de la guerra.

\section{Referencias}

Anderson, B. (1991). Imagined communities: Reflections on the origin and spread of nationalism. Londres: Verso. 
Azar, E. (1990). The management of protracted social conflicts: theory and cases. Dartmouth: Dartmouth publishing company.

Benjamin, W. (2003). La obra de arte en la época de su reproductibilidad técnica. México: Ítaca.

Canudo, R. (1995). Manifeste des sept arts. París: Séguier.

Capra, F. y Litvak, A. (dir.) (1943). Why we fight: Prelude to war [DVD]. Estados Unidos: U.S. Army Special Services.

Centro Nacional de Memoria Histórica (2013). iBasta ya! Bogotá: Centro Nacional de Memoria Histórica.

Cifras \& Conceptos (2014). La encuesta elecciones 2014. Recuperado de http://cifrasyconceptos.com/productos-polimetrica/

Cruz, M. y Gaviria, C. (dirs.) (2013). Tres Caínes [Serie de televisión]. Bogotá: RCN Televisión.

Departamento Administrativo Nacional de Estadística (2005). Manual Técnico Censo General 2005. Recuperado dehttps://www.dane.gov.co/files/censos/ManualTecnico.pdf

DepartamentoAdministrativo Nacional deEstadística (2013). Encuesta Nacional deCalidad de vida 2012. Recuperado de www.dane.gov.co/index.php/estadisticas-por-tema/ salud/calidad-de-vida-ecv/encuesta-nacional-de-calidad-de-vida-2012

Fernández, G. (2011). Joseph Goebbels y sus 11 principios de la propaganda nazi. Recuperado de https://gonzaloantinwo.wordpress.com/2011/o9/14/ joseph-goebbels-11-principios-propaganda-nazi/

Fuenzalida, V. (1998). Situación de la televisión pública en América Latina. Diálogos de la comunicación, 53, 89-119. Recuperado de http://www.consejoinfancia.gob. ar/wp-content/uploads/2012/o5/53ValerioFuenzalida.pdf

Guerrero Apráez, V. (2012). Construcciones sobre cine. Bogotá: Con las uñas.

Harlan, V. (dir.) (1940). Jüd Suss [DVD]. Berlín: Terra Filmkunst.

Keska, M. (2004). La búsqueda de la obra de arte total en el cine contemporáneo: Derek Jarman. Espacio, tiempo y forma, Serie VII, H. a del Arte, t. 17, 295-306. Recuperado de http://e-spacio.uned.es/fez/eserv/bibliuned:20703/Documento.pdf

Laclau, E. (2005). La razón populista. México: Fondo de Cultura Económica.

Lasswell, H. (1948 [1927]). Propaganda techniques in the World War. Nueva York: Knopf. 
Ley 975/2005, de 25 de julio, por la cual se dictan disposiciones para la reincorporación de miembros de grupos armados organizados al margen de la ley, que contribuyan de manera efectiva a la consecución de la paz nacional y se dictan otras disposiciones para acuerdos humanitarios.

Ley 1448/2011, de 10 junio, por la cual se dictan medidas de atención, asistencia y reparación integral a las víctimas del conflicto armado interno y se dictan otras disposiciones.

López de la Roche, F. (2013). Del uribismo doctrinario a la recuperación santista del espíritu liberal en la comunicación. En M. Dantas (coord.), Avances en los procesos de comunicación en América Latina (pp. 211-256). Buenos Aires: Consejo Latinoamericano de Ciencias Sociales.

López de la Roche, F. (2014). Las ficciones del poder: patriotismo, medios de comunicación y reorientación afectiva de los colombianos bajo Uribe Vélez (2002-2010). Bogotá: Penguin Random House.

Machado, A. (2000). El paisaje mediático: sobre el desafío de las poéticas tecnológicas. Buenos Aires: Universidad de Buenos Aires.

Mas Manchón, L. (2011). Estructura del discurso televisivo: hacia una teoría de los géneros. Cuadernos de Información, 29, 77-90.

Martín-Barbero, J. (2003). De los medios a las mediaciones: cultura y hegemonía. Bogotá: Convenio Andrés Bello.

Medina, M. y Barrón, L. (2010). La telenovela en el mundo. Palabra Clave, 13(1), 77-97. Recuperado de http://www.redalyc.org/pdf/649/64916293005.pdf

Moreno, C. y Mora Ortega, L. (dirs.) (2012). Escobar, el patrón del mal [Serie de televisión]. Bogotá: Caracol TV.

Ramsbotham, O., Miall, H. y Woodhouse, T. (2011). Contemporary conflict resolution (3. ${ }^{\mathrm{a}}$ ed.). Malden, MA: Polity Press.

Rating Colombia (2013, marzo 4): 4 de Marzo: Caínes Del Rating. Recuperado de http:// www.ratingcolombia.com/2013/o3/4-de-marzo-caines-del-rating.html

Registraduría Nacional del Estado Civil (2014, junio 15). Elección de presidente y vicepresidente, segunda vuelta. Recuperado de http://www.registraduria.gov. co/-Elecciones-2014,1995-.html

Sanguinetti, H. (2001). Verdi y Wagner: ideologías paralelas. Recuperado de https:// www.ancmyp.org.ar/user/files/Verdi_y_Wagner-Horacio_Sanguinetti-2001.pdf 
Tufte, T. (2007). Soap operas y construcción de sentido: mediaciones y etnografía de la audiencia. Comunicación y Sociedad, 8, 89-112. Recuperado de http://www. redalyc.org/pdf/346/34600805.pdf

Verdi, G. (1842). Nabucco. Milán: Teatro La Scala.

Wagner, R. (1876). Anillo del Nibelungo. Bayreuth: Festspielhaus.

Williams, R. (1989). Raymond Williams on television: selected writings. Londres: Routledge. 